\title{
Opfer tot, Tumor lebendig
}

Auf dem Krankenhausfriedhof einer österreichischen Kleinstadt werden merkwürdige, pilzartige Wucherungen gefunden. Ein junger Arzt hat einen ungeheuerlichen Verdacht: Könnte es sich dabei um Geschwüre handeln, die in den Überresten von Krebstoten weiter wachsen? Eine makabre Vorstellung! Zum Glück ist sie nur der Fantasie einer berühmten Schriftstellerin entsprungen. Gleichwohl berührt die Kurzgeschichte wissenschaftliche Tatsachen: Bestimmte Tumoren überleben ihre Opfer. Dazu gehören beispielsweise die klonal übertragbaren Tumoren beim australischen Beutelteufel.

\section{Von welcher Autorin stammt die Kurzgeschichte?}

A Patricia Highsmith

B Daphne Du Maurier

C Mary Shelley

\section{Der Buchstabe der richtigen Antwort ist}

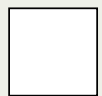

\section{Name}

Straße, Nr.

PLZ, Ort

Was ich noch sagen wollte ...

Coupon bitte ausfüllen und abschicken an Springer Medizin Verlag $\mathrm{GmbH}$ Redaktion Im Focus Onkologie - Quiz 5/2016 Aschauer Straße 30, 81549 München

Oder senden Sie uns eine E-Mail an doris.berger@springer.com

Einsendeschluss: 13.06.2016
Moritz Borchers

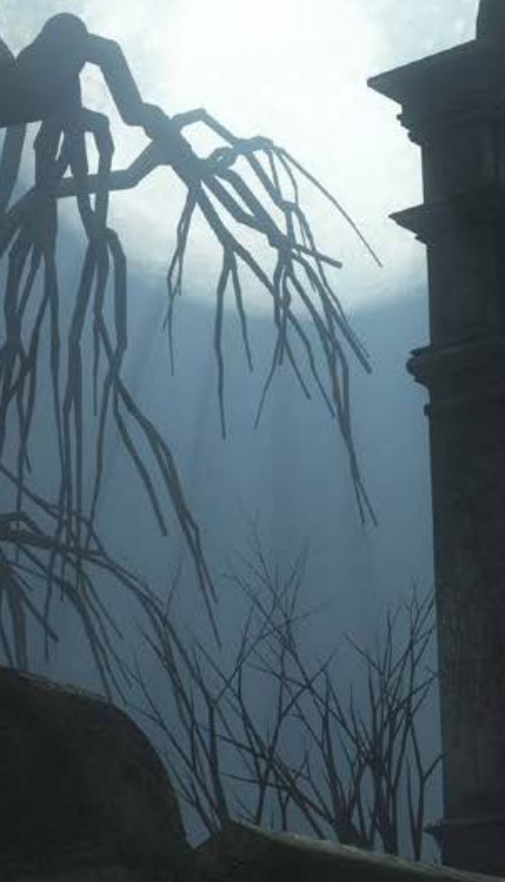

Und das können

Sie gewinnen ...

Alles, was Wissen schafft.

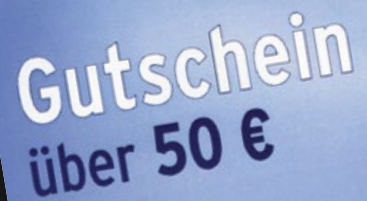

Q Springer Medizin

Lösung des Quiz 03/2016 Richtig war: C

Unter den richtigen Einsendungen verlosen wir drei Gutscheine über 50 Euro, die Sie für ein beliebiges Springer-Buch einlösen können.
U. Holtkamp, Köln

H. Keller, Ahorn

B. Bilsing, Schönebeck

Herzlichen Glückwunsch! 